


\title{
PROGRAMA DE ACOMPANHAMENTO DE ATIVIDADES MINERÁRIAS APLICADOS A PLANO BÁSICO AMBIENTAL EM DUTOVIAS: ESTRUTURA E PROCEDIMENTOS
}

\author{
MONITORING PROGRAM OF MINING ACTIVITIES \\ APPLIED TO BASIC ENVIRONMENTAL PLAN \\ IN PIPELINES: STRUCTURE AND GUIDELINES
}

\begin{abstract}
F. A. G. V. Reis ${ }^{1}$, L. do C. Giordano ${ }^{2}$, G. A. de Medeiros ${ }^{3}$, L. E. Da S. Cerri ${ }^{4}$, J. E. Zaine S. de A. Mascaro ${ }^{6}$, T. Pilachevsky' J. J. C. de Macedo ${ }^{8}$, D. de P. Amendola ${ }^{9}$ L. S. V. Domingues ${ }^{10}$, A. L. C. Christianini ${ }^{11}$, CS. M. Andrade ${ }^{12}$, G. Lumiatti ${ }^{13} \&$ M. Lunardi ${ }^{14}$
\end{abstract}

Resumo - O licenciamento ambiental no Brasil é estruturado para ter basicamente três grandes etapas, que são: fase de planejamento, na qual é solicitada a Licença Prévia;

\footnotetext{
${ }^{1}$ Geólogo e Eng. Civil. Prof. Assistente do Departamento de Geologia Aplicada da Universidade Estadual Paulista Júlio de Mesquita Filho - UNESP - Rio Claro; e-mail: fabioreis@rc.unesp.br

${ }^{2}$ Ecóloga. Doutora em Geociências e Meio Ambiente pela UNESP - Rio Claro; e-mail: lcg@rc.unesp.br

${ }^{3}$ Agrônomo. Prof. Assistente do Curso de Engenharia Ambiental da UNESP - Sorocaba; e-mail: gerson@ sorocaba.unesp.br

${ }^{4}$ Geólogo. Prof. Adjunto do Departamento de Geologia Aplicada - UNESP - Rio Claro; e-mail: lescerri@ rc.unesp.br

${ }^{5}$ Geólogo. Prof. Adjunto do Departamento de Geologia Aplicada - UNESP - Rio Claro; e-mail: jezaine@ rc.unesp.br

${ }^{6}$ Ecóloga. Doutoranda do Curso de Pós-Graduação em Geociências e Meio Ambiente - UNESP - Rio Claro; e-mail: sofiamascaro@uol.com.br

${ }^{7}$ Geógrafa. Mestranda do Curso de Pós-Graduação em Geociências e Meio Ambiente - UNESP - Rio Claro; e-mail: tatipila@gmail.com

${ }^{8}$ Graduando do Curso de Geologia - UNESP - Rio Claro; e-mail: jgcmacedo@hotmail.com

9 Graduando do Curso de Geologia - UNESP - Rio Claro; e-mail: daniloamendola@hotmail.com

${ }^{10}$ Graduando do Curso de Engenharia Ambiental - UNESP - Rio Claro; e-mail: lucas.vercellino@gmail.com

${ }^{11}$ Graduanda do Curso de Engenharia Ambiental - UNESP - Rio Claro; e-mail: analuizachristianini@gmail.com

12 Graduanda do Curso de Engenharia Ambiental - UNESP - Rio Claro; e-mail: andracarol@gmail.com

${ }^{13}$ Graduanda do Curso de Engenharia Ambiental - UNESP - Rio Claro; e-mail: gabi-lumiatti@hotmail.com

${ }^{14}$ Graduando do Curso de Geologia - UNESP - Rio Claro; e-mail: marina.lunardi@gmail.com
} 
fase de instalação, referente à Licença de Instalação; e fase de operação, associada à Licença de Operação. Para solicitação da Licença de Instalação, um dos documentos exigidos é o Plano Básico Ambiental (PBA), que apresenta o detalhamento das atividades e açôes referentes aos Programas Ambientais propostos pelo empreendedor no Estudo de Impacto Ambiental (EIA). Dentre esses Programas Ambientais, o Programa de Acompanhamento de Atividades Minerárias é exigido somente quando o empreendimento ocasiona alguma interferência em processo minerário que está registrado no Departamento Nacional de Produção Mineral (DNPM), não importando a fase de licenciamento mineral que esse processo esteja. Nesse contexto, a implantaçáo de novos sistemas de dutos ocasionam, em geral, interferências em direitos minerários, que precisam ser avaliados para verificar se haverá necessidade de indenização aos titulares desses direitos. Portanto, o presente artigo foi elaborado com o intuito de propor uma estrutura e organização para elaboração do Programa de Acompanhamento de Atividades Minerárias aplicados a dutovias, considerando os procedimentos técnicos a serem implantados para a aplicação efetiva do programa.

Palavras-chave - Atividades minerárias; Programas ambientais; Dutovias; Brasil

Abstract - The environmental licensing in Brazil is structured to have three major steps, which are: planning phase, in which it requested the Preliminary License, installation phase, on the Installation License, and the operation phase, associated with the Operating License. To request the Installation License, a document required is the Basic Environmental Plan (PBA), which provides a detail of activities and actions related to environmental programs proposed in the Environmental Impact Assessment (EIA). Among these environmental programs, the Monitoring Program of mining activities is required only when the project causes some interference in the mining process that is registered in the National Department of Mineral Production (DNPM), regardless of the mineral phase of licensing this process is. In this context, the deployment of new pipeline systems cause in general, interference with mining dues, that must be evaluated to verify if there is need for compensation to the holders of such dues. Therefore, this article was prepared with the intention to propose a structure and organization for the elaboration of Monitoring Program of mining activities applied to pipelines, considering the technical procedures to be implemented for the effective implementation of the program.

Keywords - Mining activities; Environmental programs; Pipelines; Brasil

\section{1 - Introdução}

O Programa de Acompanhamento de Atividades Minerárias (PAAM) é dos programas estabelecidos para compor o Plano Básico Ambiental (PBA) no licenciamento de atividades e empreendimentos em áreas rurais que precisam ser desapropriadas e que possuem substâncias minerais em exploração ou em pesquisa, ou seja, em áreas onde há direitos minerários ativos por meio de processos registrados no Departamento Nacional de Produção Mineral (DNPM), órgão público, ligado ao Ministério de Minas e Energia, que regulamenta, analisa, outorga e fiscaliza direitos minerários no território brasileiro. 
O PBA é um documento que abrange o detalhamento dos programas socioambientais propostos no estudo de impacto ambiental e no relatório de impacto ambiental (EIA/Rima) e pelas exigências e recomendaçóes do órgão ambiental estabelecidas na Licença Ambiental Prévia, devendo compor a documentação para solicitação da Licença Ambiental de Instalaçáo (DER, 2007; SANCHEZ, 2008). Um desses programas socioambientais que podem ser exigidos no PBA é o PAAM.

Os empreendimentos e atividades que geralmente precisam incluir o PAAM no PBA são os seguintes: dutos em geral, rodovias, ferrovias, linhas de transmissão, agroindústrias, hidrovias, reservatórios para qualquer finalidade, ou seja, todos os empreendimentos que ocupam áreas rurais que precisam ser desapropriadas. Nessas áreas é muito comum a existência de processos minerários em diferentes fases de licenciamento junto ao Departamento Nacional de Produção Mineral (DNPM).

A finalidade do PAAM é que o empreendimento em licenciamento siga os padrốes técnicos de segurança com relação à interferência de terceiros, assegurando os direitos dos titulares de processos DNPM e superficiários com contrato de arrendamento firmado.

As interferências das atividades minerárias ocorrem em várias fases do projeto de licenciamento, seja no planejamento, implantação e operação, podendo ocasionar problemas técnicos, sociais, econômicos e ambientais a uma diversidade grande de atores (SANCHEZ, 2008).

Portanto, a elaboração do PAAM é de fundamental importância para estabelecer procedimentos e diretrizes para que tanto o empreendimento em licenciamento quanto os titulares de direitos minerários não sofram prejuízos. E que no caso da operação de ambos empreendimentos, não haja interferências que possam acarretar danos para as partes envolvidas, para a comunidade de entorno e o meio ambiente em geral.

\section{2 - Objetivo}

O objetivo principal do presente trabalho é apresentar proposta de estrutura e organização do Programa de Acompanhamento de Atividades Minerárias aplicados a dutovias, considerando os procedimentos técnicos a serem implantados para a aplicação efetiva do programa.

\section{3 - Metodologia utilizada}

Para desenvolvimento do presente trabalho foi realizada pesquisa documental, analisando Planos Básicos Ambientais - PBA de empreendimentos que necessitam estabelecer o PAAM como um de seus programas e Termos de Referência emitidos por órgãos ambientais de licenciamento e empresas públicas e privadas para compor os editais de licitaçóes de obras.

Em complemento, foi realizada pesquisa bibliográfica sobre os seguintes temas: Planos Básicos Ambientais, Programas de Acompanhamento de Atividades Minerárias, aspectos ambientais, legais e de licenciamento que envolvem dutovias e extraçóes minerais.

Os resultados foram analisados de forma integrada buscando compor uma proposta para elaboração de PAAM que possa auxiliar profissionais durante o processo de licenciamento ambiental. 


\section{4 - Resultados obtidos}

A partir das análises realizadas foi elaborada proposta para estrutura e organização do PAAM, que abrange os seguintes aspectos:

- justificativas e objetivos para implantação do programa;

- definição de metas e indicadores para acompanhamento da efetividade das açóes executadas, estabelecendo as responsabilidades por cada atividade e o público alvo a que se destina o programa;

- $\quad$ procedimentos metodológicos para sua execuçáo;

- $\quad$ atendimento aos requisitos legais;

- recursos necessários e estratégias para efetiva implantação e execução do programa;

- cronograma;

- procedimentos de acompanhamento e avaliação das atividades; e,

- $\quad$ esultados e produtos esperados.

A seguir são apresentados o conteúdo e os procedimentos propostos.

\section{1 - Justificativas e objetivos}

A implantação e execução do PAAM se justifica devido a presença de atividades minerárias localizadas nas áreas de influência do empreendimento, principalmente na Área de Influência Direta (AID) e na Área Diretamente Afetada (ADA) pode ocasionar problemas nas estruturas, na faixa de dutos e nos terminais, acarretando riscos a população do entorno, aos funcionários de ambas as empresa e ao meio ambiente.

O PAAM foca na prevenção de problemas que podem afetar as áreas de influência do empreendimento por atividades minerárias, especialmente aqueles associados à ocorrência de processos geológicos de dinâmica superficial (erosão, assoreamento, movimentos de massa, inundaçóes) e vibraçóes em taludes de lavra, praça de operaçóes, depósitos de rejeito, estéril e minério e demais áreas de mineração.

Nesse contexto, o objetivo geral de um PAAM é propor estratégias para o equacionamento das questóes legais e técnicas junto aos órgãos responsáveis, referentes às interferências dos processos de licenciamento mineral nas áreas de influência do empreendimento (ADA e AID) e promover a correta gestão de eventuais interferências entre as atividades de extração mineral e as de construção e operação do empreendimento.

Para tanto deve ser considerada a legislaçáo específica, em especial o Código de Mineração e seus regulamentos, respeitando, desta forma, os detentores de direitos minerários.

\section{2 - Definição de metas e indicadores}

As metas do PAAM devem ser estabelecidas considerando as fases de instalação e operação e as áreas de influência do empreendimento (AID e ADA), envolvendo de forma geral os seguintes aspectos: 
- atualização de $100 \%$ dos processos minerários junto ao Departamento Nacional de Produção Mineral (DNPM) em relação ao levantamento efetuado durante a elaboraçáo do Estudo de Impacto Ambiental (EIA);

- identificação de áreas de interferência entre as áreas de influência do empreendimento e as atividades minerárias, apresentando a situação atual dos processos de lavra e de pesquisa mineral;

- acompanhamento das providências tomadas pelos órgãos licenciadores em relação às lavras informais existentes nas áreas de influência;

- $\quad$ estabelecimento dos procedimentos a serem seguidos para negociação de acordos com os titulares de direitos minerários e superficiários com contrato de arrendamento de extração e para monitoramento das atividades minerárias e de novos processos;

- estabelecimento dos procedimentos de bloqueio das atividades minerárias, por meio do Plano de Bloqueio de Atividades Minerárias;

- acompanhamento e monitoramento das atividades minerárias que ocorrem nas áreas de influência, para verificação dos padróes e procedimentos técnicos adotados pelas minerações;

- inserção de medidas de proteção nos planos e relatórios dos processos minerários, especialmente, no Plano de Aproveitamento Econômico (PAE), Plano de Lavra (PL), Plano de Pesquisa e Relatório Final de Pesquisa (RFP), que os titulares de direitos minerários, deverão considerar para evitar possíveis interferências com o empreendimento; e,

- bloqueio de $100 \%$ das atividades minerárias na faixa de domínio do empreendimento.

Como indicadores para acompanhamento do PAAM, devem ser considerados, no mínimo, os seguintes:

- $\quad$ quantidade de processos minerários junto ao DNPM de acordo com a fase de licenciamento;

- $\quad$ quantidade de processos minerários e lavras em atividade por municípios. Esse indicador possibilita organizar as estratégias de levantamento de campo e monitoramento das atividades minerárias;

- paralisação das atividades informais que estão inseridas nas áreas de influência do empreendimento;

- porcentagem de acordos firmados entre o empreendedor e os titulares de direitos minerários e superficiários em relação ao total de titulares e superficiários identificados nas áreas de influência;

- quantidade de Termos de Ajuste de Conduta, ou documento similar, entre o empreendedor e empresas mineradoras que operem junto às áreas de influência;

- quantidade de áreas de extração com uso de explosivos e de circulação intensa de máquinas e equipamentos pesados;

- ocorrência de processos de dinâmica superficial reais e potenciais;

- quantidade de não-conformidades identificadas em mineraçôes e quantidade de novos processos minerários e novas áreas em lavra nas áreas de influência; e,

- publicaçáo no D.O.U. de despacho do Diretor Geral do DNPM deferindo o pedido de bloqueio à emissáo dos novos títulos minerários da área ocupada pelo trecho de faixa do empreendimento. 


\section{3 - Procedimentos metodológicos}

Os procedimentos metodológicos necessários para o desenvolvimento do PAAM podem ser sintetizados da seguinte forma:

1a Etapa: Levantamento dos Processos Minerários na Faixa do Empreendimento

Para levantamento dos processos minerários inseridos na faixa do empreendimento, devem ser utilizados os dados disponibilizados pelo Banco de Dados SIGMine (Informaçôes Geográficas da Mineração) do Departamento Nacional de Produção Mineral (DNPM) e a faixa do empreendimento a ser desapropriada.

Para a realização do procedimento são necessárias 8 passos, que foram estabelecidos no presente estudo, que são as seguintes:

- $\quad 1^{\circ}$ Passo: realizar o download dos arquivos referentes aos polígonos das áreas requeridas em formato Shapefile (*.shp), diretamente do site http://sigmine.dnpm. gov.br/, considerando os dados referentes ao 20 Distrito/DNPM (São Paulo);

- 2o Passo: importar os dados para o Programa ArcGIS 9.2, em conjunto com as informaçôes geográficas (curvas de nível, drenagens, rodovias, ferrovias, limites de município e de área urbana, delimitaçóes de sub-bacias e UGRHIs - Unidades de Gerenciamento de Recursos Hídricos) vetorizadas das Cartas do Instituto Brasileiro de Geografia e Estatística (IBGE), na escala 1:100.000.

- 3o Passo: gerar uma faixa poligonal de $800 \mathrm{~m}$ no entorno dos traçados dos dutos, ou seja, um buffer $400 \mathrm{~m}$ para cada lado do traçado do duto, sendo posteriormente feita uma análise espacial entre esse polígono gerado e os dados importados do SIGmine. Nesse contexto, devem ser localizados e exportados os processos que apresentaram alguma porção da área de sua poligonal dentro do limite do buffer.

- 40 Passo: apresentar a listagem de todos os processos em uma tabela para possibilitar a descrição de sua situação legal por meio das informaçóes disponibilizadas no banco de dados do DNPM denominado Cadastro Mineiro, disponível no site https://sistemas.dnpm.gov.br/SCM/extra/site/admin/dadosProcesso.aspx.

- 50 Passo: descrever e organizar as informaçóes sobre a situação de cada processo, que devem ser apresentados em uma ficha padronizada na qual serão inseridos os seguintes dados:

(i) Números da ficha e do processo DNPM;

(ii) Fase atual do processo;

(iii) Titular atual (pessoa física ou jurídica) e CNPJ/CPF;

(iv) Responsável técnico e CPF;

(v) Substâncias minerais e tipo de uso;

(vi) Município e estado;

(vii) Título Atual expedido pelo DNPM e data de publicação do mesmo no Diário Oficial da União (D.O.U.);

(viii) Vencimento do título mineral;

(ix) Descrição da poligonal, incluindo área (ha); cota máxima e mínima (no caso de depósitos minerais subterrâneos); latitude e longitude do Ponto de Amarração 
(P.A.); comprimento, ângulo e rumo do vetor de Amarração; latitude e longitude de cada vértice da poligonal, conforme padrão adotado pelo DNPM;

(x) Histórico do processo, com descrição e data de cada evento registrado pelo DNPM no cadastro mineiro;

(xi) Figura disponibilizada pelo DNPM no cadastro mineiro, ressaltando a poligonal do processo em questáo e as poligonais dos processos no entorno; e,

(xii) Descriçóes e observaçóes do trabalho de campo, com fotografias da área caso seja desenvolvida extração mineral no local.

Também devem ser elaboradas fichas de campo para as possíveis áreas de extração mineral não legalizadas, as quais devem conter as seguintes informações: localização, provável substância explorada, análise da situação atual da lavra e caracterização por meio de fotografias;

- 60 Passo: devem ser inseridas as informaçóes disponibilizadas no Cadastro Mineiro nas fichas padronizadas dos processos DNPM, sendo que as informaçóes de campo somente devem ser inseridas após o levantamento da segunda etapa;

- 7o Passo: elaborar Mapa das Atividades Minerárias, na escala 1:50.000, contendo as informaçóes geográficas já descritas anteriormente e as poligonais com os números dos processos; e,

- $\quad$ 80 Passo: realizar análise quantitativa por meio da tabulação da quantidade dos processos DNPM, considerando os seguintes dados: fase atual do processo, municípios e substâncias minerais.

Os dados obtidos nessa etapa devem servir de subsídios para desenvolver a segunda etapa, quando devem ser realizados os levantamentos de campo.

\section{2a Etapa: Levantamento de Campo}

A partir das informaçôes obtidas na primeira etapa são estabelecidas as diretrizes para o desenvolvimento da segunda etapa, ou seja, são definidas as diretrizes para o desenvolvimento dos trabalhos de campo. Dessa forma, é elaborada uma listagem considerando os processos que apresentarem atividades de pesquisa ou algum tipo de extraçáo, de acordo com os eventos do histórico do Cadastro Mineiro.

Com base nessas informaçôes, realiza-se o trabalho de campo para verificar as possíveis interferências que podem ocorrer com o empreendimento a ser implantado, enfocando: áreas com atividade de pesquisa mineral ou lavra para a obtenção de dados mais detalhados em campo.

3a Etapa: Elaboração do Plano de Bloqueio de Atividades Minerárias

O Plano de Bloqueio de Atividades Minerárias é um documento complementar ao programa, no qual definidas:

- as diretrizes para solicitação do bloqueio, junto ao Departamento Nacional de Produção Mineral;

- como será realizado o bloqueio de novos requerimentos; 
- como os titulares de direitos minerários que estão dentro da faixa de implantação do empreendimento serão notificados formalmente sobre o bloqueio; e,

- as diretrizes gerais para negociação dos acordos entre o empreendedor e os titulares dos direitos minerários e superficiários com contrato de extração mineral.

O Plano de Bloqueio de Atividades Minerárias deve ser protocolado no DNPM, em conjunto com o instrumento legal de declaração de utilidade pública, considerando o memorial descritivo da faixa. Também será apresentada listagem com os processos minerários atravessados pelo traçado do empreendimento.

\section{4a Etapa: Relatório da Implantação do Plano de Bloqueio de Atividades Minerárias}

Nessa etapa deve ser elaborado o relatório relativo à implantação do Plano de Bloqueio de Atividades Minerárias, contendo as fichas padronizadas e todas as informaçóes obtidas nas etapas anteriores, atualizadas durante a construçáo do empreendimento.

Além das fichas padronizadas com todos os dados dos processos identificados na faixa do empreendimento e das lavras minerais informais, devem ser enfocadas no relatório, por meio de uma listagem, as principais interferências reais e potenciais de atividades minerárias com o empreendimento durante sua implantação.

\section{4 - Conclusóes}

Dentre os programas ambientais que fazem parte do Plano Básico Ambiental, o Programa de Acompanhamento de Atividades Minerárias (PAAM) é um dos menos difundidos, pois, não se aplica a todos os casos de licenciamento de empreendimentos.

Entretanto, em empreendimentos que afetem áreas rurais que necessitam ser desapropriadas, como é o caso da construção e ampliação de redes de dutos, o PAAM é obrigatório, devendo abranger os procedimentos e estratégias para adequar as questóes legais e técnicas referentes às interferências de atividades minerárias nas áreas de influência do empreendimento.

O levantamento bibliográfico e documental demonstrou que há pouca discussão sobre o conteúdo, estrutura e organização de um PAAM. Portanto, a proposta apresentada nesse artigo estabelece o conteúdo necessário para elaboraçáo do PAAM, possibilitando uma discussão sobre o tema e fornecendo subsídios para profissionais que atuam na área de licenciamento ambiental.

Como também abre a possibilidade de comparação e discussão com os procedimentos adotados em outros países que possuem problemas semelhantes.

\section{Referências Bibliográficas}

DER (2007) - Departamento de Estradas de Rodagem. Elaboração do Plano Básico Ambiental para Licença Ambiental de Instalação. Disponível em: ftp://ftp.sp.gov.br/ftpder/normas/gestao_ambiental/IP-DE-S00-004_ Plano_Basico_Ambiental_Licenca_Instalacao.pdf. Disponível em:15/07/2011

SÁNCHEZ, L.E. (2008) - Avaliação de Impacto Ambiental: conceitos e métodos. São Paulo: Oficina de textos. 495 p. 